\title{
AN INTERPRETATION OF THE FACTOR CONTENT ON TRADE
}

\author{
Alan V. DEARDORFF \\ The University of Michigan, Aime Arbor, MI 48109-1220, USA \\ Robert W. STAIGER \\ Stanford University, Stanford, CA 94305, USA \\ Received December 1986, revised version received May 1987
}

This paper shows that the factor content of trade can be used to indicate effects of trade on relative factor" prices. Factor prices in two trading equilibria can be compared by comparing instead their two 'ecuivalent autarly equilibria' constructed by changing factor endowments by the factor content of trade. Using relationships between autarky factor prices and factor endowments, several relationships are derived bzteveen factor prices with trade and its factor content. The most genaral result is a positive correlation between relative changes in the factor content of trade, appropriately ncranalized, and proportional changes in factor prices.

\section{Introduction}

The factor content of trade is well known to be useful as a way of formulating versions of the Heckscher-Ohlin Theorem that will be valid even under circumstances in which the commodity composition of trade is indeterminate. ${ }^{1}$ This in turn has led to measurement of the factor content of trade as a means of applying and testing the Theorem empirically. ${ }^{2}$ We argue in this paper that the factor content of trade is also useful as an indicator of the effects of trade on relative factor prices. Thus, for example, measurement of the factor content of trade can be used as an indicator of which factors of production have gained the most from trade relative to autarky, making it unnecessary actually to observe an autarky equilibrium in order to answer this question.

To show this, we note first in section 2 that, under fairly general conditions, a trading equilibrium has the same factor prices as an equivalent

*This paper was written with partial support from the Ford Foundation. We would like to thank Bob Stern and two anonymous referees for their belpfui comments on an earlier draft.

iSee Melvin (1968) and Vanek (1968).

ZLeontief (1954) actually measured the factor content of trade in obtaining his famous Paradox, which Stern and Maskus (1981) bave re-sviluated as sungngted by Leamer (1980). Factor content has also been used more recently as the basis for tests of the Heckscher-Ohlin Theoren by Harkness (1983), Bowen, Leamer and Sveikauskas (1987), and Staiger (1987). 
autarky equilibrium that can be constructed by changing factor endowments by the amounts of the factor content of trade. Thus, factor prices in two trading equilibria can be compared by comparing instead their two equivalent autarky equilibria. Since factor prices in autarky are related to factor endowments, it follows that factor prices with trade are related to its factor content. ${ }^{3}$

To derive a formal statement of this result, we first examine in section 3 a model in which all preferences and production functions are Cobb-Douglas. In this model, the unitary elasticities of substitution that prevail in all activities imply a very strong relationship between autarky factor prices and endowments. This in turn gives us a similarly strong relationship involving the factor conient of trade.

In sections 4 and 5, then, we turn to the much weaker relationship that exists more generally between autarky factor prices and endowments: the fact, as shown for example by Dixit and Norman (1980), that the two are negatively correlated. In section 4 , we use this result to derive a similar relationship involving the factor content of trade and the effects of trade on factor prices. We then use this relationship in section 5 to obtain several corollaries that establish correlations between these two variables. In our most general result, proved as corollary 3.4 in section 5, we establish a positive correlation beiween relative changes in the factor content of trade, appropriately mormalized, and the proporticnal changes in the corres;onding factor prices.

Section 6 concludes by noting certain limi tations of this result.

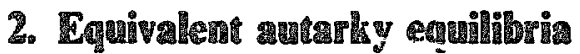

Consider an eccnomy cepable of producing $n$ goods, $X_{1}, \ldots, X_{n}$, using $m$ primary factors, $L_{1}, \ldots, L_{m}$. Let $t \epsilon$.hnology be non-joint and linearly homogeneous, so that techniques of production can be characterized by $m \times n$ matrices $A=\left\{a_{i j}\right\}$, whose elements are the quantities of factor $i$ used in producing one unit of good $j$. Let $F$ be the set of all such matrices of techniques that can be used.

A competitive production equilibrium for this economy can be defined for any given endowments of the factors, $L^{0}=\left(L_{1}^{0}, \ldots, L_{m}^{0}\right)^{\prime}$ and prices of the goods, $p^{0}=\left(p_{1}^{0}, \ldots, p_{n}^{0}\right)^{\circ}$. Such an equilibrium will consist of a vector of factor

\footnotetext{
${ }^{3}$ The relationship between post-trade factor prices and the factor content of trade has been explored by several authors. Heipnan (1984) derives a relationship between bilateral post-trade factor price differentials and the factor content of bilateral trade. Neary and Schweinberger (1986) derive a relationship between changes in the factor content of a country's trade and the factor price vector in the original equilibrium. We focus here on the relationsinip between changes in the factor content of a country's trade and changes in its factor prices. Hence, in contrast to previous work, our resu"'s allow inferences to be inade concerning the effects of trace on relative İactor prices.
} 
prices, $w^{0}$, a vector of outputs, $X^{0} \geqq 0$, and a matrix of techniques $A^{0} \in F$ such that

$$
\begin{aligned}
& A^{0} X^{0} \leqq L^{0}, \\
& p^{0 \prime} X^{0}-w^{0 \prime} A^{0} X^{0} \geqq p^{0 \prime} X-w^{0 \prime} A X, \text { for all } X \geqq 0, A \in F .
\end{aligned}
$$

That is, (2.1) says that $X^{0}$ is feasible given the factor endowments $L^{0}$ and (2.2) says that it yields at least as great a profit as any other vector of outputs that competitive producers might attempt to produce. Since a strictly positive profit in any activity could always be improved upon simply by expanding output, while a negative profit could be eliminated by contracting output to zero, (2.2) implies the following:

$$
\begin{aligned}
& w^{0 \prime} A^{0} \geqq p^{0}, \\
& p^{0 \prime} X^{0}=w^{0 \prime} A^{0} X^{0},
\end{aligned}
$$

so that unit cost equals price for each good that is produced and total profit is zero.

Now suppose that the economy is in a trading situation, and that a vector of goods $C^{0}$ is being demanded. The difference between production and demand, $T^{0}=X^{0}-C^{0}$, is the net trade vector. We do not necessarily assume that trade is either balanced or free. Nor need we assume anything special about the properties of the rest of the world, e.g. that technologies are internationally identical.

Deîne the factor content of trade, $S^{0}$, as the vector of factors needed to produce what is exported, less the factors needed to produce replacements for what is imported:

$$
S^{0}=A^{0} T^{0} .
$$

Note that (2.5) measures the economy's factor content of trade according to It: s.wn matrix of techniçues, $A^{0.4}$

Define an equivalent autarky equilibrium as an equilibrium that would arise if the original economy's factor endowments were changed by the amounts in $S^{0}$, net factor exports being removed and net factor imports

\footnotetext{
This is therefore not the same measure of factor content that was used in Deardorff (1982) to generalize various versions of the Heckscher-Ohlin Theorem. There, factor content was defined in terms of the factc's actually used in producing traded goods in the exporting country. Our use of hume-country techniques here has the advantage of being easier to apply, and indeed this is the definition implicitly used in Leontief's (1954) classic study. It should be noted, however, that the factor content of trade as defined here need not add up to zero across countries.
} 
being added, and the economy were not allowed to trade. We show, under one additional assumption, that an equivalent autarky equilibrium exists in which outputs equal $C^{0}$ and prices of both goods and factors are the same as prevailed in the original trading equilibrium. The additional assumption is that the economy is initially incompletely specialized, in the sense that it produces a positive amount of each good that it consumes. Since goods that are not consumed at all are not very interesting, we will simply assume that all outputs are strictiy positive:

$$
X^{0}>>0 \text {. }
$$

Proposition 1. If factor endowments in the economy are $B^{0}=L^{0}-S^{0}$, then with the same goods prices, $p^{0}$, as prevailed in the trading equilibrium, a competitive production equilibrium exists in which outputs are $C^{0}$, factor prices are $w^{0}$ and techniques are $A^{0}$.

Proof. We need only establish that relationships analogous to (2.1) and (2.2) hold in the new equilibrium. These are established as follows:

$$
\begin{aligned}
A^{0} C^{0} & =A^{0}\left[X^{0}-\left(X^{0}-C^{0}\right)\right] \\
& \leqq L^{0}-A^{0} T^{0} \\
& =L^{0}-S^{0}=B^{0}
\end{aligned}
$$

where the inequality follows from (2.1). Thus with the new endowments it is feasible to produce the oundle of goods, $C^{0}$. To see that such production also maximizes profits, note that (2.6) together with (2.3) and (2.4) imply that price equals average cost in all industries:

$$
p^{0}=w^{0} A^{0},
$$

and thus that production of $C^{0}$ with techniques $A^{0}$ yields zero profit, which is the best that one can do when facing $p^{0}$ and $w^{0}$ :

$$
\begin{aligned}
& P^{0} C^{0}-w^{01} A^{0} C^{0}=0 \\
& =p^{0} X^{0}-w^{0} A^{0} X^{0}
\end{aligned}
$$

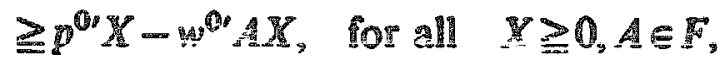

where the last inequality follows from (2.2) Q.E.D. 
Proposition 1 deals oniy with the production side of the economy. However, since the same bundie of goods is demanded in this new equilibrium as in the initial trac "ng equilibrium, end the same domestic prices prevail, it is an equilibrium for demand as well. ${ }^{5}$

The intuition behind this result may be appreciated by noting in (2? that; with full employment of all factors, $B^{0}$ is the factor content of consumpiivn, $A^{\circ} C^{0}$. Thus, the equivalent autariky equilibrium merely endows the economy with the factors needed to produce what it consumes, and thus obviates the need for trade at prevailing prices of goods and factors.

The significance of this result shouici also be explained. It means that factor prices in any non-specialized trading equilibrium can be inferred from an equivalent autarky equilibrium based on factor endowment $L-S$, where $L$ is the endowment in the trading equilibrium and $S$ is the factor content of trade in the trading equilibrium measured with the techniques of production used by the home country in the trading equilibrium. Since factor prices can be somewhat easier to specify theoretically in autarky than in trade, this result can be very useful. In the following sections we use it to relate factor prices to the factor content of trade.

\section{Strong results with a Cobb-Donglas medel}

Now consider an economy with the very strong property that wif prieferences and production functions are Cobb-Douglas. This assumption allows us to derive autarky factor prices explicitly as functions of factor endowments, and thus use the result of section 2 to get a strong relationship between factor prices and the factor content of trade.

Cobb-Douglas production functions imply that each factor earns a constant share of the revenue in each industry. Cobb-Douglas preferences imply similarly that conse ners spend a culusiant fraction of their total expenditure, $E_{z}$ on each good. In autarky, where consumer expenditure on a good equals the revenue of the industry producing that good, the two together imply that each factor's total income (from employment in all industries together) is a constant fraction of consumer expenditure. Letting that constant for factor $i$ be $c_{i}$, we have:

$$
w_{i} L_{i}=c_{i} E
$$

${ }^{5}$ One also needs to check that there is still income sufficient to purchase the goods. If in the initial equilibrium producors and consumers were faced with the same prices, $p^{0}$, then factor incoune in the equivalent autarky equilibrium would exactly equal $p^{0 \%}, 0^{\circ}$. Notice that any tariff revenue in the trading equilibrium can be safely ignored here, since direct production of the consumaption bundle $C^{0}$ generates eamed income sufícient to purchase it, even if that was not the case with trade. On the other hand. 1 domestic taxes in the initial trading equilibrium caused producer and consumer prices to divergs, ahem appropriate transiers thay be mentessary. 
Were we to divide through by $L_{l}$, we would have immediately that autarky factor prices are inversely related to factor endowments.

Now consider for this economy two equilibria, numbered 1 and 2 , that may involve trade. With trade, (3.1) does not apply directly. However, we can use the result of section 2 to express factor prices with trade in terms of what they would be without trade in an equivalent autarky equiliorium, the factor endowments of which are $B=L-S$. Thus, letting $L^{0}$ be the actual factor endowments, assumed the same in both trading equilibria, the price of factor $i$ can be expressed as:

$$
w_{i}^{h}=c_{i} E^{h} /\left(L_{i}^{0}-S_{i}^{h}\right), \quad h=1,2
$$

If we now compare factor prices in the two equilibria, we have:

$$
\frac{w_{i}^{2}}{w_{i}^{1}}=\frac{E^{2}\left(L_{i}^{0}-S_{i}^{j}\right)}{E^{1}\left(L_{i}^{0}-S_{i}^{2}\right)}
$$

Thus, factor prices depend positively on levels of expenditure and inversely on endowments net of the factor content of trade. The result can be simplified if we normalizi prices in both equilibria so that total expenditure is unity. Then the expenditure ratio in (3.3) drops out, and we can express the relative change in factor prices between the two equilibria in terms of the change in the factor content of trade relative to the factor content of consumption:

Proposition 2. If a country's preferences and technologies are Cobb-Douglas and identical in two trading equilibria for which factor endowwents are also identical, then if prices are normalized to equate total expenditure so unity in both equilibrias,

$$
\frac{w_{i}^{2}-w_{i}^{1}}{w_{i}^{1}}=\frac{\mathbb{S}_{i}^{2}-\mathbb{S}_{i}^{1}}{B_{i}^{2}}
$$

Sor every factor $i$.

Finally, instead of comparing two trading equilibria, we can compare a single rrading equilibrium with the autarky equilibrasan that would have obrained with the same endowments. Letting $1=t$ be the trading w wilibrium and $2=a$ be the autarky equilibrium, and noting that trade and its factor content are zero in autarky, we get the following very simple relationship: 
Corollary 2.1. Under the assumptions of Proposition 2, if one of the equilibria is itself an autarky equilibrium, then for any factor $i$ :

$$
\frac{w_{i}^{p}-w_{i}^{0}}{w_{i}^{t}}=\frac{S_{i}^{n}}{L_{i}^{0}} .
$$

Thus, if we consider the move from autarky to any trading equilibrium for this Cobb-Douglas country, the factor content of trade as a fraction of each factor endowment is an exact measure of the fraction of each factor price that can be attributed to that trade.

These are very strong results, but they are not quite as strong as they may at first appear. They do not indicate in any absolute or real sense what the effects of trade and changes in trade will be on factor prices. Instead, they indicate only the effects on factor prices relative to one another. That is, if (3.5) is negative, for example, this does not necessarily mean that the price of factor $i$ has fallen in real terms or in any relevant nominal terms. It does, however, mean that the price of factor $i$ has fallen relative to the prices of other factors which are determined by (3.5) to have increased.

What the factor prices here represent can be seen more clearly by considering the particular normalization we have chosen. By equating nominal aggregate expenditure, $E$, in the two equilibria being compared, we make factor prices reflect the shares of aggregate expenditure earned by a unit of each factor. If prices and aggregate expenditure happened to be such as to yield a constant level of aggregate welfare, then these factor prices would indeed measure welfare. But in general aggregate welfare does change between the two equilibria and this interpretation is generally not possible.

For example, in the comparison of autarky and trade in (3.5), it is normally the case that aggregate welfare rises with trade. Thus, the effects on welfare of individual factors include both the effects on their shares of aggregate welfare described by (3.5), plus their shares of the usual gains from trade. It follows that, while we can be sure that factors for which (3.5) is positive do gain from trade, other factors for which (3.5) is megative may gain from trade as well, if the aggregate gain from trade is large enough to offset the relative loss indicated by (3.5). That a nat loss is nonetheless possible, however, is well known from the Stolper-Samulson Theorem.

\section{Weak results with a more general model}

Without a strong assumption such as Cobb-Douglas preferences and production functions, there does not exist in general a relationship between factor endowments and autarky factor prices that is strong enough to hold for each and every factor. Variations of complementarity and substitutability 
among goods and factors - which are ruled out by the Cobb-Douglas assumption - can cause prices of particular factors to move in ways that contradict the changes in their own factor endowments. A factor that is closely substitutable for another factor, for example, may rise in price even though its endowment rises, if the endowment of its close substitute shrinks sufficiently. These problems with relating factor prices and endowments in autarky also make it difficult to derive any generally valid strong relationship between factor prices and the factor content of trade that holds for every factor of production.

However, a general result is possible if we look for a reiationship that holds on average across all factors. In a model like that of section 3 but without the Cobb-Douglas restriction, Dixit and Norman (1980, p. 99) derived the following simple relationship between autarky factor prices and factor endowments:

$$
\left(w^{1}-w^{2}\right)^{\prime}\left(L^{1}-L^{2}\right) \leqq 0,
$$

where factor prices, $w^{1}$ and $w^{2}$, are those that correspond to endowments, $L^{1}$ and $L^{2}$, respectively, in autarixy. For this result they required oniy that preferences be homothetic, that production functions be linearly homogeneous and non-joint, and that prices of goods be normalized so that aggregate nominal expenditure is the same in both equilibria, just as we did in section 3.

Dixit and Morman interpret (4.1) as showing that 'autarky factor price differences are negatively correlated with endowment differences'. This is not strictly correct, but it is true that (4.1) imposes an imporiant restiction ori the relationship between endowments and autarky factor prices that is related to a correlation."

If we now draw on the result of section 2, we can compare factor prices in srading equilibria in terms of their equivalent autarky equilibria.

Proposition 3. Let $w^{i}$ be the vector of factor prices in a non-specialized trading equilibrium in which the factor endowments are $\mathbb{L}^{\circ}$ and the factor

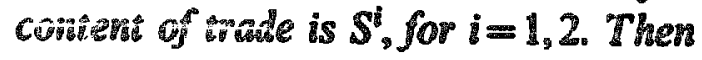

$$
\left(w^{1}-w^{2}\right)\left(\mathbb{S}^{1}-S^{2}\right) \geqq 0 \text {. }
$$

\footnotetext{
5ahe inequality in (4.1) directly immilies the sign of a correlation if either of the two vectoss in the inner product thas zero mean. See Deardorfi (1980). In this case factor endowments could easily all move in the same direction, while the normalization on goods prices prevents us from imposing a similar normalization on lactor prices. It remains to be seen what sort of true correlation results can be derived from (4.1).
} 
Proof. From section 2, factor prices, $w^{i}$ are the same as would obtain in an autarlyy equilibrium with factor endowments $L^{0}-S^{i}$, and we can therefore replace the factor endowments in (4.1) with these exiressions,

$$
\left(w^{1}-w^{2}\right)^{\prime}\left[\left(L^{0}-S^{1}\right)-\left(L^{0}-S^{2}\right)\right] \leqq 0,
$$

and (4.2) then follows. Q.E.D.

This is the basic general result of this paper. It establishes a simple correlation-like relationship between changes in factor prices and changes in the factor content of trade. If, between two trading equilibria, the factor content of trade rises for some factors and falls for others, this says that the prices of the former will tend to rise relative to the prices of the latter.

As in section 2, it is also possible to compare a trading equilibrium with autarky. Ieting $1=t$ and $2=a$ in (4.2), and noting that the factor content of trade is zero in autarky, we have:

Corollary 3.1 .

$$
\left(w^{l}-w^{2}\right)^{\prime} S^{t} \geqq 0 .
$$

Thus, the effect of trade relative to autarky is to tend to raise the returns to those factors which are exported in factor content terms relative to those which are imporand.

\section{Corollaries involving true correlations}

The simple results just derived, as already noted, are not the same as true correlations. Further assumptions and further work are needed to derive true correlations from them, and to determine therefore whether the results tell us anything meaningful about the models from which they derive.

Such correlations are particularly easy to derive if it happens to be the case that there exist factor prices subject to which the factor content of trade is balanced. Thus, we have:

Corollary 3.2. If the factor content of trade is balanced when valued at some vector of factor prices, $w^{0}$, then there is a non-negative correlation between changes in the value of the factor content of trade at these factor prices and the changes in the factor prices themselves relative also to $w^{0}$ :

$$
\operatorname{Cor}\left[\frac{\left(w_{i}^{1}-w_{i}^{2}\right)}{w_{i}^{0}}, w_{i}^{0}\left(S_{i}^{1}-\mathbb{S}_{i}^{2}\right)\right] \geqq 0
$$


Also, comparing a trade equilibrium witi autarky,

$$
\operatorname{Cor}\left[\frac{\left(w_{i}^{i}-w_{i}^{R}\right)}{w_{i}^{0}}, w_{i}^{0} S_{i}^{t}\right] \geqq 0 .
$$

These results follow immediately from the assumption of balanced factor tradi, since it implies that the sums of the second arguments in these correlations are zero and thus have zero means. ${ }^{7}$

These results would be most useful only in cases where the factor content of trade actually is balanced at one of the prevailing sets of factor prices. Unfortunately, only with free trade is this likely to be the case:

Corollury 3.3. If commodity trade is free and balanced at morld prices, $p^{w}$, then

$$
\operatorname{Cor}\left[\frac{\left(w_{i}^{f}-w_{i}^{g}\right)}{w_{i}^{f}}, w_{i}^{f} S_{i}^{f}\right] \geqq 0
$$

where $w^{f}$ and $S^{f}$ are the vectors of factor prices and the factor content of trade that exist with free trade.

Broof. With incomplete specialization, so that (2.3) holds with equality, we have

$$
w^{f} S^{f}=w^{f} A^{f} T^{f}=p^{f} T^{f}=0,
$$

so that factor trade is balanced at free-trade factor prices and we can apply Corollary 3.2. Q.E.D.

This is a useful result for the theoretical world of free and balanced trade, but unfortunately it does not apply to the more relevant world of impediments to trade. And in the latter world, there is in general no reason to expect factor trade to be balanced even when goods trade is. Tariffs, for example, permit countries to consume bundles of goods that are worth more, at domestic prices, tuan what they produce, and this in general causes the factor content of their trade valued at domestic factor prices to appear to be in deficit.

Indeed, is is possible in general for the factor content of trade to be negative for all factors, and it is possible similarly for changes in the factor content of trade to be in the same direction for all factors. In such cases the above corollaries, which rely at a minimum on trade in at least some factors going in opposite directions, are of little use. What is needed is a relationship

${ }^{7}$ See Deardorff (1980). 
between factor prices and factor trade that focuses instead on the relative magnitudes.

One such result can be obtained by comparing the value of the change in factor content of trade to what it would be if all factor contents were to change in the same proportion to factor consumption. That is, let

$$
B^{1}=L^{0}-S^{1}
$$

be the factor content of consumption in the initial equilibrium. As a measure of the relative change in the factor content of trade for each factor, $i$, we then define:

$$
\Delta_{i}=w_{i}^{1}\left(S_{i}^{2}-S_{i}^{1}\right)-\left[\frac{w_{i}^{1} B_{i}^{1}}{w^{1} B^{1}}\right]\left[w^{11}\left(S^{2}-S^{1}\right)\right] .
$$

From this, $\Delta_{i}$ is positive if the value of the change in factor- $i$ trade is greater than its 'share' of the value of the total change over all factors, where its share [in large brackets in (5.6)] is the expenditure share on factor $i$ in equilibrium 1. Note also that, from its definition, it follows immediately that

$$
\sum_{i} \Delta_{i}=0 \text {. }
$$

With this definition of the change in the relative factor content of trade at our disposal, we can now state the most general correlation result of the paper.

Corollary 3.4. If factor prices are normalized on the vector of factor content of consumption in equilibrium 2, then there is a nonnegative correlation between changes in relative factor prices and relative changes in the factor content of trade as defined in (5.6):

$$
\operatorname{Cor}\left[\frac{\left(w_{i}^{2}-w_{i}^{1}\right)}{w_{i}^{1}}, \Delta_{i}\right] \geqq 0 .
$$

Proof. In addition to the two equilibria, 1 and 2, being compared, consider a third equilibrium for this economy, numbered 3, with the property that the factor consent of consumption is proportional to that in equilibrium 1 but equal in value, at factor prices $w^{2}$, to that in equilibrium 2 . That is, define a vector $\boldsymbol{S}^{3}$ such that

$$
\mathbb{L}^{0}-\mathbb{S}^{3}=\mathbb{B}^{3}=\lambda \mathbb{B}^{1}
$$


and

$$
w^{1 \prime}\left(L^{0}-S^{3}\right)=w^{1 \prime} B^{3}=w^{1 \prime} B^{2}
$$

Substituting (5.9) into $(5.10), \lambda$ can be determined as

$$
\lambda=\frac{w^{1} \mathbb{B}^{2}}{w^{10} \mathbb{R}^{1}}
$$

and thus

$$
\begin{aligned}
S^{3} & =L^{0}-\lambda B^{1} \\
& =L^{0}-\mathbb{B}^{1}+(1-\lambda) B^{1} \\
& =\mathbb{S}^{1}+\frac{w^{1} B^{1}-w^{1 /} B^{2}}{w^{2} \cdot \mathbb{B}^{1}} B^{1} \\
& =S^{1}+\frac{w^{10}\left(S^{2}-S^{1}\right)}{w^{1} B^{1}} B^{1} \\
& =S^{1}+\Gamma B^{1},
\end{aligned}
$$

where $\Gamma$ is defined as

$$
\Gamma=\frac{w^{10}\left(S^{2}-S^{1}\right)}{w^{10} B^{1}}
$$

Using the assumed homogeneity of techology and homotheticity of preferences, $(5.9)$ implies that this new equilibrium has the same prices of both goods and factors as equilibrium $\mathbb{1}$,

$$
w^{3}=w^{\mathbb{1}}, \quad p^{3}=p^{1}
$$

and that consumption is proportional to that in equilibrium 1 ,

$$
C^{3}=\lambda C^{1}
$$

Suppose now that the vector of factor content of consumption in equilibritum 2 is used as numeraire. That is, factor prices are normalized so that

$$
w^{2 \cdot} \mathbb{B}^{2}=w^{2} \mathbb{B}^{3} .
$$


It follows that

$$
\begin{aligned}
p^{3} C^{3} & =p^{\prime \prime} \lambda C^{1} \\
& =\lambda w^{3 \prime} A^{1} C^{1} \\
& =\lambda w^{1 \prime} B^{1} \\
& =\frac{w^{\prime \prime} B^{2}}{w^{1 \prime} B^{1}} w^{1 \prime} B^{1} \\
& =w^{\prime \prime} B^{2} \\
& =w^{2 \prime} B^{2} \\
& =w^{2 \prime} A^{2} C^{2} \\
& =p^{2 \prime} C^{2} .
\end{aligned}
$$

Thus, we can apply Proposition 3 to a comparison of equilibria 2 and 3 :

$$
\left(w^{3}-w^{2}\right)\left(S^{3}-S^{2}\right) \geqq 0
$$

Writing this inner product as a summation, using (5.12) and (5.14), this becomes:

$$
\begin{aligned}
0 & \leqq \sum_{i}\left(w_{i}^{3}-w_{i}^{2}\right)\left(S_{i}^{3}-S_{i}^{2}\right) \\
& =\sum_{i}\left(w_{i}^{1}-w_{i}^{2}\right)\left(S_{i}^{1}-\$_{i}^{2}+\Gamma B_{i}^{1}\right) \\
& =\sum_{i}\left[\frac{w_{i}^{2}-w_{i}^{1}}{w_{i}^{2}}\right]\left[w_{i}^{1}\left(S_{i}^{2}-S_{i}^{1}\right)-\Gamma w_{i}^{1} B_{i}^{1}\right] \\
& =\sum_{i} \frac{w_{i}^{2}-w_{i}^{1}}{w_{i}^{2}} \Delta_{i} .
\end{aligned}
$$

From (5.7) and the definition of correlation, (5.8) ifan tollows: Q.E.D.

\section{Corchus}

We have already mentioned the hact that our results relate only to relative actor prices, and should not be viewed as indicating which factor prices go See Deardorfî (1980). 
up and down absolutely or in real terms. This qualification needs to be repeated and stressed, since there will inevitably be a strong temptation to regard a positive or negative factor content of trade as automatically associated with an absolute gain or loss from trade. But this could be quite misleading.

An example of why it may be misleading arose in another paper [Staiger, Deardorff and Stern (1988)], where we used the Michigan Computationai Model of World Production and Trade to calculate changes in trade due to trade barriers and then computed the corresponding changes in the factor content of that trade. In one instance we found the factor content of a country's trade to rise for ail factors when another country raised tariffs. This was tiue even though we required balanced trade in our calculations, and it seemed to suggest that all of the country's factors had gained from the foreiga tariff. This is not the case, however.

What happened, as we have already suggested in section 5 , was that the foreign tariff had caused a worsening of the country's terms of trade - a fall in the prices of its exports relative to its imports - requiring a rise in the quantities of exports and/or a fall in the quantities of imports in order to keep trade balanced. Thus, the factor content of trade increased. But this clearly does not imply a gain for all factor owners, since the worsening of the terns of trade implies that the country as a whole has suffered a loss.

However, this calculation aiso illustrates the usefulness of the result put forward in this paper. It is much easier to measure the factor content of trade, and even to estimate how the factor content of trade will change in response tô policy, thas it is is to estimate empirically the ccmplete effects of trade on factor markets. Thus, the factor content of trade can be used as a mansageable indicator of what the effects of trade and trade poiicy may be on factor rewards. Even though the effects that are captured are only relative, this can still be a very useful piece of inforriation.

Just how complete this information is depends, clearly, on the nature of preferences and production functions. As section 3 indicates, if a country is well approximated by Cobb-Douglas preferences and technologies, then the factor content of trade provides an accurate measure of relative effects on factor prices that holds for each individual factor. On the other hand, if variations in substitutability among factors are important, then only the average relationships of sections 4 and 5 can be established.

\section{Deferences}

Bowen, M.P. E.E. Leamer and L. Sveikauskas, 1987, Multicountry, multifiactor iests of the factor abundance theory, American Economic Review 77, 791-32s.

Deardorff, A.V., 1980, The general validity of the law of comparative advantage, Joumal of Political Economy 88, $941-957$. 
Deardorff, A.V., 1982, The general validity of the Heckscher-Ohlin theorem, American Economic Review 72, 683-694.

Dixit, A.K. and V. Norman, 1980, Theory of international trade (Cambridge University Press, London).

Harkness, J.P., 1983, The factor-proportions model with many nations, goods and factors: Theory and evidence, Review of Economics and Statistics 55, 298-305.

Helpman, E., 1984, The factor content of foreign trade, The Economic Journal 94, 89-94.

Leamer, E, 1980, The Leontief paradox, reconsidered, Journal of Political Economy 88, 495-503.

Leontief, W., 1954, Domestic production and foreign trade: The American capital position reexamined, Economia Internazionale 7.

Melvin, J.R., 1968, Production and trade with two factors and three goods, American Economic Review 58, 1248-1268.

Neary, J.P. and A.G. Schweinberger, 1986, Factor content functions and the theory of international trade, The Review of Economic Studies 53, 421-432.

Staiger, R.W., 1987, A specification test of the Heckscher-Ohlin theory, Journal of International Economics, forthcoming.

Staiger, R.W., A.V. Deardorff and R.M. Stern, 1988, The effects of protection on the factor content of Japanese and American foreign trade, Review of Economics and Statistics, forthcoming.

Stern, R.M. and K.E. Maskus, 1981, Determinants of the structure of U.S. foreign trade, Journal of International Economics 11, 207-224.

Vanek, J., 1968, The factors proportions theory: The n-factor case, Kyklos 4, 749-756. 